The final, definitive version of this paper has been published in The British Journal of Occupational Therapy, Vol/Issue, Month/2016 by SAGE Publications Ltd, All rights reserved. @ C Cameron J, Sadlo G, Hart A and Walker C]]. DOI: 10.1177/0308022615627176

URL:

\title{
Return-to-work support for workers with mental health problems: Identifying and responding to key challenges of sick leave.
}

Abstract

Introduction: This research explored return-to-work and sick leave experiences of workers with mental health issues in contact with acute or community mental health services.

Method: Using a critical realist methodology with a comparative case study and collaborative design, 21 employed participants recovering from mental health problems participated in semi-structured interviews. Data were analysed using inductive and deductive thematic and constant comparative analysis.

Findings: While on sick leave, despite a range of challenges, participants treasured their work identities. They were sustained by positive and troubled by negative memories of work. People missed the routine of work and felt isolated. To varying degrees of success, they searched for alternative activities to fill this gap and promote recovery.

Conclusion: The need for sick leave was not disputed, but an important discovery was its iatrogenic ('side-') effects, whereby isolation and reduced activity levels could exacerbate mental health problems. Negative impacts of sick leave need to be mitigated by support to maintain worker identity and orientation and by opportunities and encouragement to sustain routine, activities and social contacts. A new concept of 'occupational capital' emerged, comprising accessible external opportunities and supports for occupational participation, and internal capacities and skills required to access these.

Key words: Return-to-work; sickness absence; mental health; job retention; iatrogenesis; occupational capital.

\section{Authors:}

1) Dr Josh Cameron, Principal Lecturer, School of Health Sciences, University of Brighton.

2) Prof Gaynor Sadlo, School of Health Sciences/Centre for Health Research, University of Brighton.

3) Prof Angie Hart, Centre for Health Research, University of Brighton.

4) Dr Carl Walker, Principal Lecturer, School of Applied Social Science, University of Brighton.

Corresponding author:

Dr Josh Cameron

School of Health Sciences

University of Brighton

Robert Dodd Building

49 Darley Rd

Eastbourne

East Sussex

BN20 7UR

UK

i.cameron@brighton.ac.uk

+44 (0)1273643648

\section{Introduction}

16.2 million days were recorded as lost in 2013 due to sickness absence for mental health problems in the UK (Office for National Statistics, 2014). This is a considerable cost to the economy, but arguably the relative impact on individual lives is greater. Risk of job loss is a major challenge for such employees with mental health problems. In the United States, Nelson and Kim (2011) found that 


\section{Return-to-work support for workers with mental health problems: Identifying and responding to key challenges of sick leave.}

people with mental health problems had a $56 \%$ increased risk of dismissal and a $32 \%$ increased risk of deciding to leave work compared to people without mental health problems. For those who do lose their jobs, the Organisation for Economic Co-operation and Development's (OECD) (2012) report presents evidence that unemployment is likely to increase the severity of mental health problems. In this context, the UK Government published its response to its commissioned independent review of sickness absence (Black and Frost, 2011; Department for Work and Pensions, 2013). This proposed a UK-wide state-funded health and work assessment, advice and intervention service to support people on sickness absence. It was subsequently renamed 'Fit for Work' and finally launched in 2015 (Department for Work and Pensions, 2014). Implementation of this policy remains a key challenge in the UK and internationally for other countries addressing similar concerns (OECD, 2012). These statistics and policy intentions underline the importance of understanding how best to help people with mental health problems retain employment.

\section{Job-retention-focused interventions}

Research into job-retention interventions for people with mental health problems is limited (Centre for Mental Health, 2014; Durand et al., 2014). The British Occupational Health Research Foundation's review of mental health job-retention intervention evidence (Seymour, 2010) reveals a shift from support for cognitive behavioural therapy-informed approaches to workplacefocused independent case management. Projects using this approach offer a range of support and advice, solution identification, and supported communication between employees and employers - notably line managers (Cameron et al., 2012; Pittam et al., 2010). A review of occupational therapy interventions supporting the employment and education of adults with severe mental illness (Arbesman and Logsdon, 2011) did not consider job-retention activities. Qualitative studies such as Strickler et al. (2009) have identified challenges and supports to job retention for individuals with shared geographic, service use or diagnostic characteristics, but tend not to differentiate between those seeking new work and those returning to an existing job. Even when job retention has been studied, there is a risk that a focus on active project interventions can mean that going on sick leave is not recognised as an intervention and consequently its intended and unintended impacts are not scrutinised.

Current research and policy highlight the need to understand more about the challenges faced by employed people with mental health problems while on sick leave, even including people still in hospital. We need deeper understanding of their experiences, attitudes and emotions while on sick leave to inform return-to-work planning in a timely manner that enhances their wellbeing. This article addresses the following research question: How do workers who are recovering from mental health problems experience their sick leave and what attitudes and emotions do they have about returning to work?

\section{Methodology}

This study adopted a critical realist methodology (Danermark et al., 2002), holding that there exists an external reality but that people's perspectives of this may vary (due to factors such as class, 


\section{Return-to-work support for workers with mental health problems: Identifying and responding to key challenges of sick leave.}

gender, ethnicity and age). Critical realist researchers consider it possible to gain explanatory insight into structures and mechanisms that shape reality using a range of analytic procedures. A critical realist perspective in social world research logically implies that other people's 'expertise by experience' should be harnessed in the research process because of the increased insights it has the potential to bring by including varied perspectives of reality. Accordingly, service user collaboration from the outset brought expertise by personal experience (McLaughlin, 2010) to the study design and analysis.

\section{Methods}

\section{Service user collaboration}

Three people with past experiences of acute mental health services while still in work formed the acute service user panel, holding 10 meetings; the community group met seven times. Participation was by open invitation to project users; four to eight attended each meeting. Agreed roles were to:

- Bring service user perspectives to research design and implementation,

- Balance/challenge professional perspectives,

- Participate in analysis of interviews,

- For the acute panel this involved reading and discussing interview transcripts.

For the community group this involved discussing provisional themes identified by the first and fourth authors. This approach, requested by the group, was to protect the anonymity of some members who had also elected to participate as interviewees.

- Participate in dissemination activities.

\section{Participants and contexts}

Participants who had been on sick leave for between four weeks and six months were recruited from two settings in the south of England: acute mental health services and a community-based job retention project for people with mental health problems. It was acknowledged that there are differences between these settings which may influence people's experiences of sick leave; however, this was on balance considered a strength, adding to the breadth of experiences that the study could collect. A key aim was to interview people during their recovery because little was understood about what people think, experience and feel they need at this point. Participants in both settings were recruited by staff passing study information sheets (which included details of how to opt in) to all service users identified as meeting inclusion criteria (notably that they were in employment and considered well enough to participate in the interviews).

\section{Data collection and analysis}

Data were collected by the first and fourth authors using semi-structured interviews which were designed to capture the depth and breadth of job-retention experiences. Acute study interviews took place on NHS premises and community study interviews at the job-retention project base. All interviews were audio recorded and subsequently transcribed. Analysis methods derived from Danermark et al.'s (2002) six stages of critical realist explanatory research using inductive and 


\section{Return-to-work support for workers with mental health problems: Identifying and responding to key challenges of sick leave.}

deductive thematic analysis. These stages were generally sequential, but there were sometimes overlaps or returns to an earlier stage. Table 1 presents each stage, its aims and the section of this paper which it principally informs. The stages were primarily conducted by the first author, drawing on service user collaboration as described above and discussion of data and emergent themes with the other authors. NVivo software supported the process of storing and coding data. These measures contributed to enhancing the rigour and trustworthiness of the research, alongside the use of a reflexive research journal by the first author.

Table 1: Data analysis adapted from Danermark et al 2002.

\begin{tabular}{|l}
\hline Stage - and aim \\
\hline 1.Description \\
- To describe the concrete data and context \\
- Informs findings section.
\end{tabular}

2. Analytic resolution

- To separate/ dissolve composite and complex elements by distinguishing components, aspects and dimensions.

- Informs findings section - notably identification of themes.

\section{Abduction}

- To view elements identified in stage 2 in contexts of different theories.

- Informs discussion section.

\section{Retroduction}

- To identify generative mechanisms and their contexts

- Informs discussion section.

5. Comparison between different theories and abstractions

- To evaluate the relative explanatory power of different mechanisms and their associated structural contexts

- Informs discussion, recommendations and conclusion.

6. Concretisation and contextualisation

- To generalise from theory to the concrete.

- Informs recommendations.

\section{Ethical issues and approvals}

Ethical approval was obtained from the university ethics committee and an NHS local research ethics committee. Issues identified and addressed were to avoid coercion whilst supporting participation, minimise risk of distress and ensure confidentiality. Pseudonyms are used throughout the reporting of the findings.

\section{Findings}

Characteristics of participants recruited from acute mental health services and the community job retention project are presented in tables 2 and 3 respectively. 


\section{Return-to-work support for workers with mental health problems: Identifying and responding to key challenges of sick leave.}

Table 2: characteristics of the 7 acute mental health service users.

\begin{tabular}{|c|c|c|c|c|}
\hline Self-reported diagnoses & $\begin{array}{l}\text { Gender } \\
\text { and } \\
\text { ethnicity }\end{array}$ & Age range & Job types & Living status \\
\hline $\begin{array}{l}2 \text { bipolar disorder, } \\
3 \text { severe depression. } 2 \text { did not } \\
\text { use specific diagnoses ( } 1 \\
\text { auditory and visual } \\
\text { hallucinations, } 1 \text { suicidal and } \\
\text { intrusive thoughts). }\end{array}$ & $\begin{array}{l}4 \text { Male } \\
3 \text { Female } \\
\text { All white } \\
\text { British }\end{array}$ & 21 to 45 & $\begin{array}{l}2 \text { factory workers (1 with } \\
\text { voluntary job also), } 1 \\
\text { supermarket worker, } 1 \\
\text { delivery worker, } 1 \text { craft } \\
\text { tutor, } 1 \text { bank clerical } \\
\text { worker, } \\
1 \text { care worker }\end{array}$ & $\begin{array}{l}3 \text { lived alone } \\
4 \text { with a partner } \\
\text { or other family } \\
\text { member(s) }\end{array}$ \\
\hline
\end{tabular}

Table 2: characteristics of the $\mathbf{1 4}$ community job retention project users

\begin{tabular}{|l|l|l|l|l|}
\hline Self-reported diagnoses & $\begin{array}{l}\text { Gender } \\
\text { and } \\
\text { ethnicity }\end{array}$ & $\begin{array}{l}\text { Age } \\
\text { range }\end{array}$ & Job types & $\begin{array}{l}\text { Living } \\
\text { status }\end{array}$ \\
\hline $\begin{array}{l}\text { A range of diagnoses - depression, bipolar } \\
\text { disorder, and schizo-affective disorder. } \\
\text { supported by primary care services, or. } \\
\text { specialist mental health services. }\end{array}$ & $\begin{array}{l}10 \text { female } \\
4 \text { male } \\
\text { All white } \\
\text { British }\end{array}$ & $29-54$ & $\begin{array}{l}3 \text { health/social care } \\
\text { professionals, } \\
3 \text { administrative } \\
\text { staff, } \\
2 \text { care workers, } \\
2 \text { non-teaching } \\
\text { roles in higher } \\
\text { education, } \\
1 \text { legal executive, } \\
1 \text { courier, } \\
1 \text { kitchen assistant } \\
1 \text { retail manager }\end{array}$ & $\begin{array}{l}1 \text { with } \\
\text { spouse }\end{array}$ \\
& & & & \\
& & & & \\
\hline
\end{tabular}

Thus, a broad range of mental health problems, severity and job types were reflected. There were more women than men, most were in their $30 \mathrm{~s}$ and $40 \mathrm{~s}$ and all were of white British origin.

Five themes were identified encapsulating these participants' experiences of sick leave and feelings about their jobs. Firstly, there was clear evidence that despite the many challenges they faced people were really treasuring their work identity. This underpinned the second theme in which people spoke of how they were sustained by positive and troubled by negative memories of work. Thirdly, participants described how much they were missing the routine of work. Fourthly, they spoke of ways in which they were feeling lonely and isolated. The fifth theme presents details of how workers on sick leave were trying out and searching for activities to do to help them cope with the challenges of being on sick leave and to recover from mental health problems.

\section{Treasuring work identity}

Worker identity was a special form of personal asset that was both jeopardised and utilised by participants. This work identity really mattered to participants during their recovery, because it influenced how they perceived themselves and how they considered others viewed them. Their disruptions to worker identity were unwelcome, and during recovery even those who disliked their jobs demonstrated hopefulness in remaining attached to the idea that work will play a role in their lives: 


\section{Return-to-work support for workers with mental health problems: Identifying and responding to key challenges of sick leave.}

There have been times when I've thought, 'Oh God I can't cope! I'm not doing this very well' and with support it's just made me feel like actually I can go ahead and that I have got certain skills, I'm not a complete waste of space, there is a future. (Laura)

Being on sick leave, Ben felt the symbolic value of earning a wage was lost, despite receiving some sick pay:

I hate not working [...] it's like an extra bit of me has been taken away, like my freedom and I don't like being at home in the evening and knowing I haven't gone out and made some money. (Ben)

Harry explicitly stated that work was important because it could help his recovery:

And my thoughts on work and mental health is that work is a really good medicine if you can manage to get back to work, even if it's just part time, it's really good for you. (Harry)

\section{Sustained by positive and troubled by negative memories of work}

Support to sustain worker identities helped some participants to feel hopeful for their future working lives and to still see themselves as competent:

I can remind me.. 'you are an asset to your company if it's done in the right way and you're not under too much pressure'. She [job retention project worker] really made me see that and it's amazing because it turned around my view of the situation. (Alice)

Participants also demonstrated that they held on to important positive experiences of doing work. Some reported enjoying challenging work tasks requiring expertise, concentration and manual skill:

... that's my favourite part of the job, I love soldering and that's what I was brought in to do ....it's really good. It's got to be spot on, the time just flies by. The [feelings of anxiety and depression] drop. They drop because l'm concentrating more and [have] less time to think of what I'm actually feeling. (Gavin)

Daniel described aspects of his voluntary rescue work in similar terms, but also gained satisfaction from the stimulation and sense of helping others:

The thing I enjoy is the buzz out of the job. A Sunday afternoon and the wind had got up and they'd broken down and mum, dad and three kids are on there, shouting and screaming and scared and you get them and calm them down. (Daniel)

By contrast, it was the lack of opportunity to use his skills in his paid work that led Daniel to feel negatively about it and, like some others, implicate it in exacerbating his mental health problems: "And that's probably what does me in as well. I'm not using my brain to [do] what I know I can do". 


\section{Return-to-work support for workers with mental health problems: Identifying and responding}

to key challenges of sick leave.

Some participants' negative views of their performance at work appeared to generate feelings of guilt and self-blame:

When pay day came around I felt like my colleagues were working hard for their money I didn't deserve maybe the full money. (Ruth).

There were some direct experiences of stigmatising and bullying behaviour of colleagues including managers that weighed on participants' minds as they contemplated return to work:

One of the guys..., about a decade ago, he had... a nervous breakdown and everyone now still goes ... 'Ooh calm down, don't have a breakdown!' ... it's always there and getting brought up and I don't really want that. (Ben)

And my mobile went, and it was my production manager. He said, 'Oh l've got a message for you. ... Just to let you know if you decide to $s^{* * *}$ [expletive] anywhere in [town] in the next three weeks I will know about it'. ... That was harassment. ... I had a few messages like that to start with. (Daniel)

Conversely, past experiences of acceptance and understanding following disclosure of their mental health problems helped others:

I went into work yesterday and that sympathetic attitude was still there, so it wasn't just a front, it was actually genuine concern, so my work have been brilliant really. (Gavin)

Actually it [a previous return to work] was better than I expected, everyone was supportive. (Yvonne)

However, Yvonne had a less positive expectation this time, which was grounded in external factors, specifically the length of sick leave, changes at work, and more people knowing about why she was off work:

So much has happened since l've been away that adds to my anxious fears of going back really. (Yvonne)

\section{Missing the routine of work}

The routine and structure provided by work was often valued:

I like the routine of having work - occupies my day. It gives me something to do. (Mark)

Being on sick leave caused an unsettling disruption to such regular routines. For Hilary, hospital admission was a measure which removed her from her routine and helped her feel safe - but did not prepare her for return: 


\section{Return-to-work support for workers with mental health problems: Identifying and responding to key challenges of sick leave.}

It's nice to be in the hospital because you're protected and you feel safe here, but you do know that your responsibilities have been taken away, but we've got to go back to all of that, so my concern is although I feel better being here, it's like your whole life's just been put on hold. (Hilary)

People found they had extra time to manage and cope with - without structure and activity to organise and fill it:

The last five weeks have seemed like five months, it just seems to drag on when you're ill - It just seems to, to just go on, and go on, and go on. (Ben)

\section{Feeling lonely and isolated.}

Participants reported more limited social contacts since they were on sick leave:

I didn't see any of my friends. I didn't. My own parents didn't come and visit me. (Yvonne)

For some, isolation arose from a direct consequence of how illness made them feel about seeing others:

I can't answer the front door, if the phone rings I never answer. It's crazy because if I went out with my friends that would alleviate the loneliness, but I don't seem to be able to do that. (Hilary)

For others, isolation seemed to be a consequence of losing social contacts at work as a result of being on sick leave:

for hours in the day I might not see anybody, whereas normally l'm talking to my customers, or having a laugh with workmates so it's quite a bit depressing. (Ben)

Faced with this, Ben initially tried to sustain work social contacts through a football club and pool tournament, but found the pressure of concealing his mental health diagnosis difficult. Daniel's attempts at social links were curtailed by concerns that this might be used as evidence by managers or colleagues that he wasn't really unwell:

Because I know if I do anything in [town], anything, you get found out, because a lot of the blokes in that company are so small-minded. You've only got to go somewhere and it's back to work. (Daniel)

Some acute study participants reported helpful informal experiences of peer support on wards or in acute day services. Community-based participants found that the more formally facilitated peer support group helped them overcome feelings of isolation:

Sometimes you think you're alone, you're experiencing a unique experience but then you come up and meet up, you find 'ah' you all face the same problem. It sort of makes you less bothered. (Steve) 


\section{Return-to-work support for workers with mental health problems: Identifying and responding}

to key challenges of sick leave.

\section{Searching for activities to do to help}

Participants deployed a range of activities, to varying degrees of success, to try and manage challenges related to being on sick and/or to their mental health problems. In many instances activities were used palliatively, attempting to mitigate or limit problems. Despite the emptiness of being on sick leave, participants tried to keep their minds and bodies occupied to fend off negative thoughts and feelings. Thus, Penny spoke of trying to "keep busy" to distract herself from suicidal ideas. Mark visited the swimming pool, an activity he chose because "I find it quite relaxing and it's a good bit of exercise". Ben tried to manage boredom and lack of stimulation by doing "sudokus and everything like that to try and keep my mind active, but no you still go a bit brain-dead". He was not alone in finding some self-initiated activities only partially effective:

Reading I find keeps my sanity really. Going out for a walk, just enjoying being with people a little bit during the day - but I realise I should be doing something productive. (Hilary)

Thus, it seems sick leave activities did not fully replace the role that work had played.

Ben found a new pursuit - weightlifting - providing some satisfying physical exertion which he had missed:

That's the only thing that makes me feel like l've done something in the day, is if I have a workout and I wake up the next day and I feel achy, I think 'Oh that's good it's worked'. (Ben)

Here there was also a sense, shared by others, that it was important to try and maintain or reintroduce some form of routine:

I've actually been trying to get myself more involved in the house. I've been doing a lot in the garden, thoroughly cleaned the car. (Daniel)

Most of the activities which participants used were of a solitary nature. Mark's attempt to go swimming - a solitary activity in a social context - was one he felt he had to curtail because "the swimming pool was crowded - so I found that a bit hard to deal with." Mark had been encouraged to try swimming by day service staff. Activities described by others were also often prompted by mental health staff. Ben was frustrated by what he considered was an emphasis on medication by mental health services. This was accompanied by a desire to be helped to find alternative ways to manage the impact of symptoms:

"They've never really said, 'Oh try this, this and this and that'll help you keep your mind off it' or anything like that, they've just more tried to focus on tablets". (Ben)

Others attended an acute day service and described the benefits of occupations:

I came into the day services here and did structured groups like pottery, creative art, gardening, things that would distract you from maybe suicidal thoughts or self-harm. (Gavin) 


\section{Return-to-work support for workers with mental health problems: Identifying and responding to key challenges of sick leave.}

\section{DISCUSSION}

As stated above, analysis of findings in critical realist research involves viewing themes through the lens of different theories, identifying generative mechanisms and their contexts, and comparing the explanatory power of different theories. These endeavours are principally set out in this discussion section, which will begin by considering findings in relation to existing research and theory centred on concepts of worker identity, hopefulness and resilient recovery. Acknowledgement of limitations of individual conceptualisations of resilience will lead into a more ecological discussion that considers the impact of occupational disruption experienced by participants whilst on sick leave and proposes that the associated mechanisms can be understood using the concept of iatrogenesis. The discussion closes by advancing a new concept of occupational capital to help explain the erosion and deployment of occupational assets seen in our findings.

\section{Worker identity, hopefulness and resilient recovery.}

Participants in this research confirmed previous theoretical understandings (Jahoda, 1982; Paul and Moser, 2009) about how disruption to engagement in working life can erode a person's sense of self, with negative impacts on confidence, mood and self-esteem. This was particularly the case where alternative activities were limited and relates to Wilcock and Hocking's (2014) thesis that the meanings people attach to activities support doing and develop their identities. Having a worker identity really mattered to participants, in part because it was under threat, but also because it had the potential to be a motivational mechanism, supporting a successful vocational and mental health recovery. This is consistent with Leufstadius et al.'s (2009) finding, in their qualitative study of Swedish people with persistent mental health problems, where meaningful work supported a sense of identity and fostered recovery.

The relationship of worker identity to motivation and hope coheres with Jahoda's (1982) conclusion that hope helped to sustain unemployed workers' continuing identification with previous trades. It is also consistent with Paul and Moser's (2009) 'incongruence model', which proposes that psychological distress is experienced by unemployed people because their motivation and aspiration to work is frustrated. Although not actually unemployed, the situation for our participants was often similar; their desire to work could be frustrated because they were on sick leave, increasing distress and - as we also found - feelings of self-blame and guilt.

Like Jahoda (1982), we found that hope could counteract these mechanisms by helping sustain concepts of the self as a worker. It has been suggested that positive self-identity is a key internal resource in promoting the resilience of people facing a range of adversities (Hart et al., 2007; Ungar et al., 2007) and our findings suggest that this applies to employees with mental health problems who are on sick leave. This may explain why many of our participants remained attached to their identification as workers, because they found it could help to anchor them in relation to the symptoms and distress that can engulf people - especially during acute episodes (Yanos et al., 2010). However, we found limitations in strategies and analysis which focus on the psychological attributes of individual employees alone. The risk is that a narrow emphasis on individual worker resilience (see, for example, Rees et al., 2015) may reinforce the self-blame and feelings of guilt expressed by participants while on sick leave and fail to respond to external problems such as those that may lie in 


\section{Return-to-work support for workers with mental health problems: Identifying and responding to key challenges of sick leave.}

job design or the attitudes and behaviours of colleagues and managers. Ecological understandings that consider how a resilient return-to-work can emerge from the worker, their workplace and their activities (Cameron et al., 2014) may be more helpful and perspectives from occupational science (Wilcock and Hocking, 2014) have potential to support this.

\section{Occupational disruption and sick leave}

Threats to worker identities arose from the suspension of participation in the occupation of work. This may have arisen because people were deprived of the affirming effects of doing work and removed from the social world of work. 'Occupational disruption' is a term that has been developed to describe the position of people who find their participation in occupations is restricted for a period of time, by factors beyond their control, to a degree which risks undermining their health and wellbeing (Whiteford, 2000). Occupational disruption is a construct relevant to the situation of people with mental health problems on sick leave: where people are not supported to retain employment, more enduring occupational deprivation may occur.

The occupational disruption experienced by participants seemed to involve missing stimulating and enriching aspects of working they had previously valued. Missing such experiences of engagement in skilled and challenging tasks is consistent with findings and theories concerning the wellbeing felt during occupational engagement (Gauntlett, 2011). Participants described using a range of other occupations to try and promote recovery. Some occupations appeared to fall into Wright et al.'s (2007) 'positive distraction' category, conferring transitory benefits. By contrast, occupations described in more enthusiastic terms aligned with the 'challenge-skills' experience which Wright et al. (2007) found had more enduring benefits.

Participants' consistent attempts to compensate for the loss of the regularity of work through other activities challenges some negative stereotypes of people with mental health problems on sick leave (Thornicroft, 2006). However, such attempts were restricted by a range of factors. Activities provided by inpatient units and acute day services, although generally valued, were limited - as has been reported elsewhere (The Schizophrenia Commission, 2012). Some were able to initiate activities themselves, but were constrained by difficulties in accessing opportunities and they were often of a solitary nature. Consistent with what Thornicroft (2006) has characterised as 'felt' or anticipated stigma, some people expressed a fear of how others might respond to them, particularly if seen publicly engaging in activity at a time when some felt the legitimacy of their absence from work was in question by both wider society and immediate colleagues and managers.

Our findings suggest occupational deprivation and disruption can be experienced even when absent from jobs that have negative or mixed appraisals. Worries about work did not disappear when participants were on sick leave - indeed, for some they appeared to grow. Despite not feeling able to work, people were struggling to cope with the loss of regular activity. This added further challenges to those they faced already, suggesting the relevance of the concept of iatrogenesis. 
Return-to-work support for workers with mental health problems: Identifying and responding to key challenges of sick leave.

\section{latrogenic effects of sick leave}

Ivan Illich (1977) used the term iatrogenesis in his seminal work on the limits of medicine. Most commonly used to describe negative side-effects of medication, iatrogenesis has the broader meaning of a 'state of ill health or an adverse event that is caused by, or is the result of, a wellintended health care intervention' (Mitty and Fleming, 2010: 369). Looking at the negative impacts of residential institutions on older people, Klein (2002) extends the concept to encompass non-medical interventions. Whilst the relevance of the concept may be readily understood by occupational therapists, no explicit application of iatrogenesis to sickness absence was identified in the literature, suggesting the negative impact may not be fully acknowledged. Labriola et al.'s (2007) large prospective survey of Danish employees provided a degree of evidence of something akin to the iatrogenic effects of sick leave, suggesting that reductions in perceived self-efficacy develop predominantly while on sick leave rather than beforehand. Fleten and Johnsen (2006) made brief reference to the concept (again without using the term), considering that their postal intervention may have been successful because it prevented the 'side effects of being sick listed' (p680) from becoming established.

latrogenesis seems very applicable to our findings. It does not dispute the need for sick leave, but draws attention to its side-effects, or unintended consequences. The iatrogenic consequences of being on sick leave may impact more on people with mental health problems, as they may combine with symptoms and associated stigma and discrimination, in a multiplicative manner (see Table 4 below).

Table 4. Examples of multiplicative combination of iatrogenic effects of sick leave, mental health symptoms and stigma/discrimination factors found in the data.

latrogenic effects $x \quad$ Mental health symptoms $x$ Stigma/discrimination factors

\begin{tabular}{|l|l|l|}
\hline social isolation & social withdrawal & $\begin{array}{l}\text { Lack of understanding of } \\
\text { mental health issues }\end{array}$ \\
\hline $\begin{array}{l}\text { reduced opportunity for } \\
\text { stimulation from participation } \\
\text { in a range of occupations }\end{array}$ & Anhedonia & being 'shunned' \\
\hline $\begin{array}{l}\text { reduced opportunities for } \\
\text { productive accomplishment }\end{array}$ & low self esteem & social exclusion \\
\hline $\begin{array}{l}\text { diminished opportunity to } \\
\text { obtain feedback from } \\
\text { occupational participation }\end{array}$ & $\begin{array}{l}\text { distorted cognitive self- } \\
\text { appraisal of capacity }\end{array}$ & excessive criticism \\
\hline
\end{tabular}

Occupational capital - a new concept to understand erosion and deployment of occupational assets

The established notion of social capital, centred on the benefits that people accrue from social networks (McKenzie and Harpham, 2006), can be used to typify changes to participants' social worlds, thereby accounting for the negative impacts of social isolation. Yet we also found negative impacts associated with diminished activity participation and some participants attempted to deploy 


\section{Return-to-work support for workers with mental health problems: Identifying and responding to key challenges of sick leave.}

non-work activities in compensation. Thus, it could be that a consequence of occupational disruption and associated iatrogenic effects experienced when on sick leave reduced occupational capital. While there are grounds for caution with regard to adding to the growing list of types of capital, and to the commodification of human activity by using terminology associated with finance, the term draws attention to what Wilcock and Hocking (2014) considered to be the neglected occupational dimension in public health. A new definition of occupational capital is accordingly proposed as: a combination of accessible external opportunities and supports for occupational participation and internal capacities and skills to access this. Occupational capital can be seen as what is lost or reduced as a result of occupational deprivation or disruption.

Both the range and extent of occupational opportunities, as well as the supports for participation, were diminished while participants were on sick leave. Capacities (notably confidence, energy, motivation) that facilitate occupational performance were also restricted by the impacts of mental health problems (including associated impacts such as stigma and discrimination). Some participants drew on formal and informal support and their own resources, and engaged in alternative activities to sustain or mitigate this loss of occupational capital. In this way, nurturing occupational capital may contribute to the resilience of workers with mental health problems, increasing the likelihood of a sustainable return to work.

\section{Implications and limitations}

People with mental health problems on sick leave need help to keep in touch with work in a way that is sensitive: firstly, to where they are in their recovery journey; and secondly, to the nature of their relationships at work - notably with line managers. Support to maintain a resilient work orientation and identity may be facilitated by explicit affirmations of people's work roles, achievements and skills, and by assistance to challenge feelings of selfblame and guilt.

The iatrogenic effects of sick leave should be very much acknowledged, and mental health workers, GPs, employers, co-workers and especially employees with mental health problems and their families should be educated to understand its potentially harmful effects. This should not be taken as grounds to question the need for sick leave - indeed, our findings suggest that to do so may add to the stigmatising attitudes that may limit people's recovery. Rather, understanding of the negative impacts of iatrogenic effects may call attention to the need to devise mitigating measures to reduce negative impacts on finance, social isolation and occupational disruption. This could include encouragement to engage in a range of activities on sick leave, and education referred to above should include recognition of the value of an 'active' sick leave. This may in turn help people return to work using existing strategies such as graded return-to-work plans and adjustments to work tasks and environments.

The principle limitations of the study relate to scale, context and participant diversity. Both case studies took place in the south of England in similar areas, involving one National Health Service Trust and one job-retention project. Furthermore, whilst a broad range of jobs were represented and both men and women included, there was no diversity in terms of ethnicity (all describing themselves as white British), and older (above 50) and younger workers (below 30) were under represented. 


\section{Return-to-work support for workers with mental health problems: Identifying and responding to key challenges of sick leave.}

Finally, the nature of the recruitment process in the acute study suggests a need for caution in the extent to which it can be assumed that similar concerns would have been raised by other employed acute mental health services users who did not volunteer.

There are many potential avenues for further research. Evidence for iatrogenic effects of sick leave - and the efficacy of strategies to mitigate these - could be explored in a broader range of settings and participants (including those with physical health conditions). Such studies could also consider further the utility of the proposed concept of occupational capital though, since the concept is not specific to the field of vocational rehabilitation, other occupational science and therapy research may also consider its relevance.

\section{CONCLUSION}

Far from being an issue that could be set aside and addressed at a later date, work mattered to employees on sick leave during their recovery because of feelings of guilt about not working, and because some feared that work had, or could, exacerbate their mental health problems. Such fears co-existed with a strong sense that work was an important part of people's lives in terms of identity, finance, social connections and the newly proposed concept of occupational capital. These assets were under threat during sickness absence, but they also had the potential to be deployed to support a resilient recovery. The established concept of social capital draws attention to the recoverypromoting benefits an individual can gain from social networks and interactions. Building on that starting point, occupational capital emphasises the importance of enabling occupational participation through a combination of internal capacities and external support. The concept of iatrogenesis was newly applied to being on sick leave, and a need to mitigate its effects (but not to question the validity of sickness absence) was a key recommendation for policy and vocational rehabilitation practice.

\section{(i) Key findings -}

Work matters to employees during recovery from mental health problems.

People on sick leave experience a loss of 'occupational capital'.

Help is needed to mitigate 'iatrogenic' impacts (side-effects) of sick leave.

\section{(ii) What the study has added}

The study increases understanding of experiences of employees with mental health problems calling attention to the iatrogenic effects of sick leave. It also proposes a new concept of 'occupational capital'.

Research ethics: This research received approval from the University of Brighton, Faculty of Health Research Ethics and Governance Committee (FREGC07/61) and the Brighton and Hove NHS Local Research Ethics Committee (05/Q1905/146)

Declaration of conflicting interest: None declared.

Funding: This research received some funding from the University of Brighton, School of Health Professions Clinical Research Centre. 


\section{Return-to-work support for workers with mental health problems: Identifying and responding}

to key challenges of sick leave.

\section{Acknowledgements}

The authors thank the members of service user advisory panels for bringing their expertise to the study despite its origins in often challenging experiences. Likewise we are grateful to the participants for sharing so openly their hopes, fears, struggles and successes. Other individuals who have provided important advice and guidance are Imogen Haslam, Vicky Edmonds, Kate Bones and Dr Graham Stew.

\section{References}

Arbesman M and Logsdon DW (2011) Occupational therapy interventions for employment and education for adults with serious mental illness: a systematic review. American Journal of Occupational Therapy, 65(3), 238-246.

Black C and Frost D (2011) Health at work - an independent review of sickness absence. London: DWP. Available at: https://www.gov.uk/government/publications/review-of-the-sicknessabsence-system-in-great-britain Accessed on 10/09/2014.

Cameron J, Hart A and Sadlo G (2014) Resilience at work. In The Second World Congress on Resilience: From Person to Society. Conference Proceedings: pp961-966. Medimond, Bologna. ISBN 978-88-7587-697-5.

Cameron J, Walker C, Hart A, Sadlo G, Haslam I, The Retain Support Group (2012) Supporting workers with mental health problems to retain employment: a qualitative study of users' experiences of a UK job retention project. Work: A Journal of Prevention, Assessment and Rehabilitation, 42(4), 461-471.

Centre for Mental Health (2014) Primary care and employment. Available at: http://www.centreformentalhealth.org.uk/employment/primary care.aspx. Accessed 20/10/2014 Danermark B, Ekstrom M, Jakobsen L and Karlsson JC (2002) Explaining Society: Critical Realism in the Social Sciences. Abingdon: Routledge.

Department for Work and Pensions (2013) Fitness for work: the Government response to 'Health at work - an independent review of sickness absence'. Norwich: DWP.

Department for Work and Pensions (2014) Fit for Work. Online: DWP. Available at: https://www.gov.uk/government/policies/helping-people-to-find-and-stay-in-work/supportingpages/co-ordinating-the-health-work-and-wellbeing-initiative\#fit-for-work Accessed on 10/11/2014. Durand M, Corbière M, Coutu M, Reinharz D, Albert V (2014) A review of best work-absence management and return-to-work practices for workers with musculoskeletal or common mental disorders. Work: A Journal of Prevention, Assessment and Rehabilitation, 48(4) 579-589.

Fleten N and Johnsen R (2006) Reducing sick leave by minimal postal intervention: a randomised, controlled intervention study. Occupational \& Environmental Medicine, 63(10), 676682.

Gauntlett D (2011) Making is connecting: the social meaning of creativity, from DIY and knitting to YouTube and Web 2.0. Cambridge: Polity.

Illich I (1977) Limits to Medicine: Medical Nemesis, the Expropriation of Health. Harmondsworth: Penguin. 


\section{Return-to-work support for workers with mental health problems: Identifying and responding to key challenges of sick leave.}

Hart A, Blincow D and Thomas H (2007) Resilient Therapy: working with children and families. London: Routledge

Jahoda M (1982) Employment and unemployment: a social-psychological analysis. Cambridge: Cambridge University Press.

Klein J (2002) latrogenesis within long term care facilities. Occupational Therapy in Health Care, 16(2-3), 91-104.

Labriola M, Lund T, Christensen KB, Albertsen K, Bultmann U, Jensen JN and Villadsen E (2007) Does self-efficacy predict return-to-work after sickness absence? A prospective study among 930 employees with sickness absence for three weeks or more. Work: A Journal of Prevention, Assessment \& Rehabilitation, 29(3), 233-238.

Leufstadius C, Eklund M and Erlandsson L (2009) Meaningfulness in work -- experiences among employed individuals with persistent mental illness. Work: A Journal of Prevention, Assessment \& Rehabilitation, 34(1), 21-32.

McKenzie K and Harpham T (2006) Social capital and mental health. London: Jessica Kingsley Publishers.

McLaughlin H (2010) Keeping service user involvement in research honest. British Journal of Social Work, 40, 1591-1608.

Mitty E and Fleming ST (2010) latrogenesis, frailty, and geriatric syndromes. Geriatric Nursing, 31(5), 368-374.

Nelson R and Kim J (2011) The impact of mental illness on the impact of employment termination. Journal of Mental Health Policy and Economics, 14(1,) 39-52.

OECD (2012) Sick on the Job? Myths and Realities about Mental Health and Work. Mental Health and Work: OECD Publishing. Available at: http://dx.doi.org/10.1787/9789264124523-en Accessed on $8 / 6 / 2015$.

Office for National Statistics (ONS) (2014) Full Report: Sickness Absence in the Labour Market, February 2014. Online: ONS. Available at:

http://www.ons.gov.uk/ons/rel//mac/sickness-absence-in-the-labour-market/2014/rpt---sicknessabsence-in-the-labour-market.html Accessed on: 07/10/2015.

Paul KI and Moser K (2009) Unemployment impairs mental health: meta-analyses. Journal of Vocational Behavior, 74(3), 264-282.

Pittam G, Boyce M, Secker J, Lockett H and Samele C (2010) Employment advice in primary care: a realistic evaluation. Health \& Social Care in the Community, 18(6), 598-606.

Rees, C.S., Breen, L.J., Cusack, L. \& Hegney, D. (2015). Understanding individual resilience in the workplace: the international collaboration of workforce resilience model. Frontiers in Psychology-Psychology for clinical settings, 6, 1-7.

The Schizophrenia Commission (2012) The abandoned illness: a report from the Schizophrenia Commission. London: Rethink Mental Illness. Available at:

http://www.schizophreniacommission.org.uk/the-report/ Accessed on 14/10/2014.

Seymour L (2010) Common mental health problems at work. What we know about successful interventions. A progress review. London: Sainsbury Centre for Mental Health, British 
Return-to-work support for workers with mental health problems: Identifying and responding to key challenges of sick leave.

Occupational Health Research Foundation. Available at:

http://www.centreformentalhealth.org.uk/pdfs/BOHRF common mental health problems at wor k.pdf Accessed 22/10/2014.

Strickler DC, Whitley R, Becker DR and Drake RE (2009) First person accounts of long-term employment activity among people with dual diagnosis. Psychiatric Rehabilitation Journal, 32(4), 261-268.

Thornicroft GJ (2006) Shunned: discrimination against people with mental illness. Oxford: Oxford University Press.

Ungar M, Brown M, Liebenberg L, Othman R, Kwong WM, Armstrong M and Gilgun J (2007) Unique pathways to resilience across cultures. Adolescence, 42(166), 287-310.

Whiteford G (2000) Occupational deprivation: global challenge in the new millennium. British Journal of Occupational Therapy, 63(5), 200-204.

Wilcock A and Hocking C (2014) An Occupational Perspective of Health. 3rd ed. Thorofare: Slack Incorporated.Wright JJ, Sadlo G and Stew G (2007) Further explorations into the conundrum of flow process. Journal of Occupational Science, 14(3), 136-144.

Yanos PT, Roe D and Lysaker PH (2010) The impact of illness identity on recovery from severe mental illness. American Journal of Psychiatric Rehabilitation, 13(2), 73-93. 